Supplement of Nat. Hazards Earth Syst. Sci., 14, 1085-1098, 2014

http://www.nat-hazards-earth-syst-sci.net/nhess-14-1085-2014/

doi:10.5194/nhess-14-1085-2014-supplement

(C) Author(s) 2014. CC Attribution 3.0 License.

(c) (1)

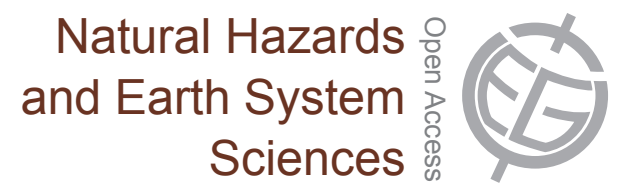

Supplement of

\title{
Robust, multifunctional flood defenses in the Dutch rural riverine area
}

\section{J. M. van Loon-Steensma and P. Vellinga}

Correspondence to: J. M. van Loon-Steensma (jantsje.vanloon@wur.nl) 


\section{Supplement 1}

This Supplement presents an impression of each of the five study-locations. The aerial photographs are from Google-earth, and the 'ground' photographs are by the authors, and by Hanneke Elema (the photograph of the Grebbedijk). The approximate location of the ground photograph is indicated by a white star.

\section{Situation Streefkerk}

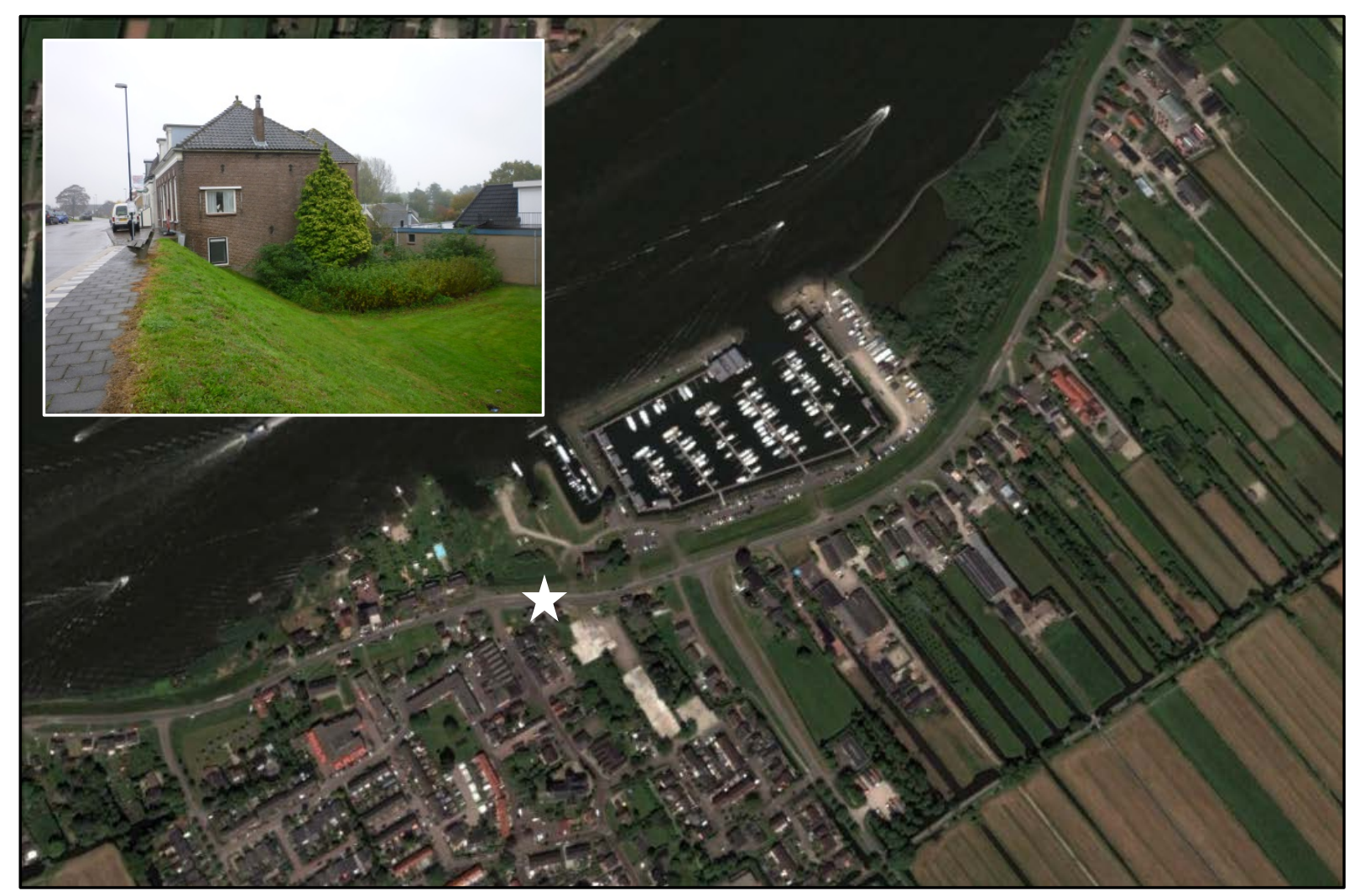




\section{Situation Marsdijk}

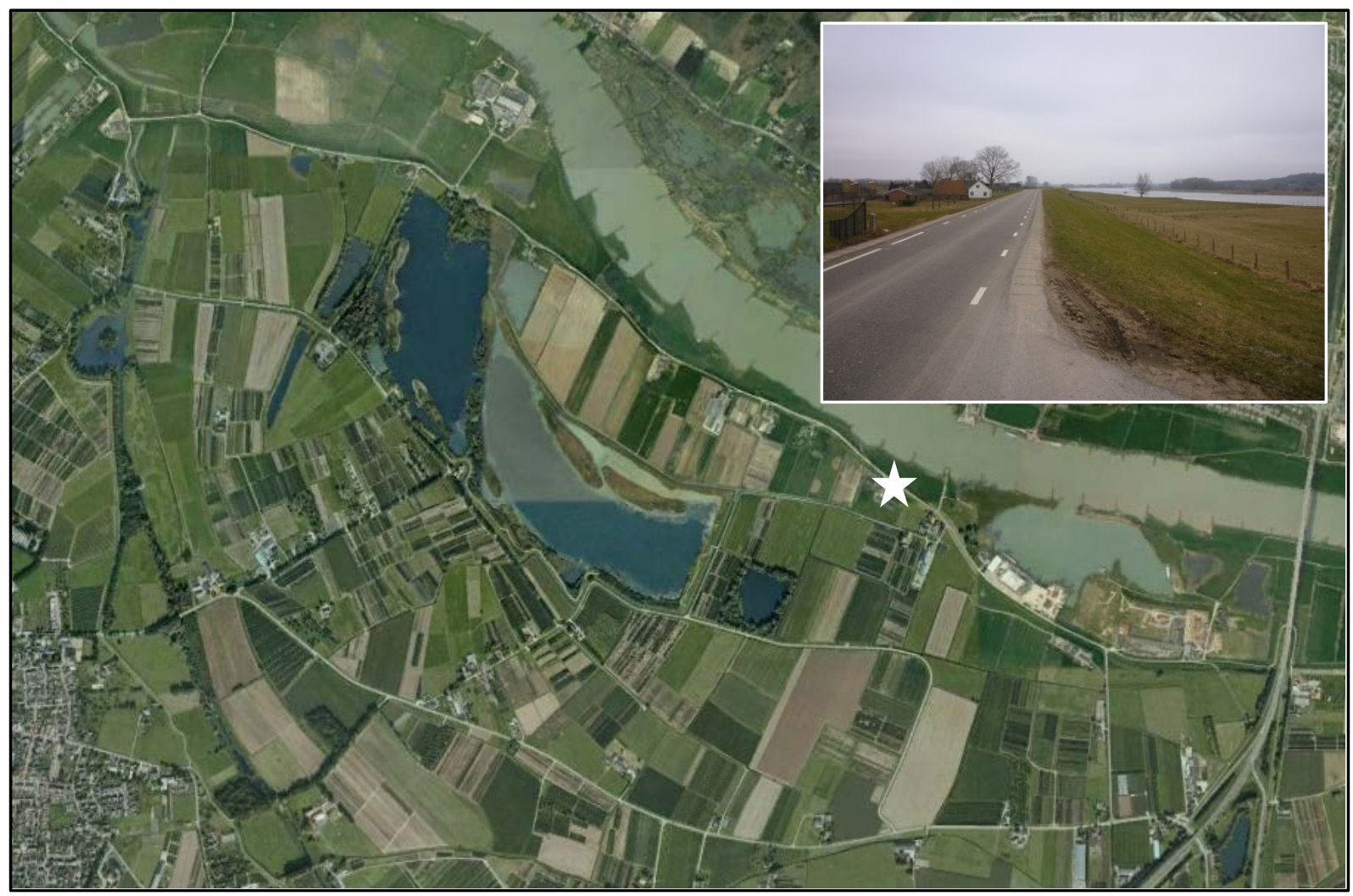




\section{Situation Arnhem (Bakenhof)}

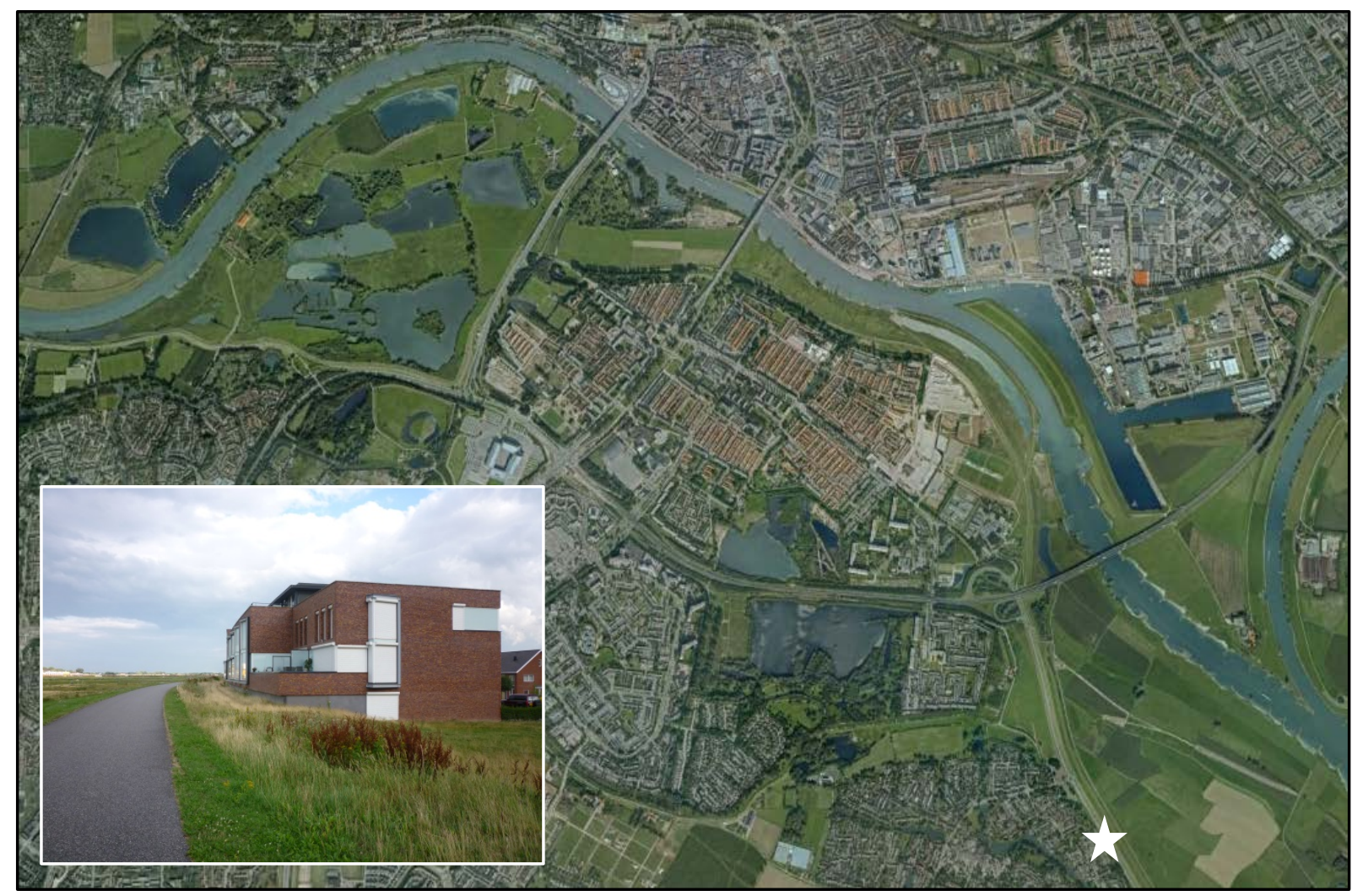




\section{Situation Grebbedijk}

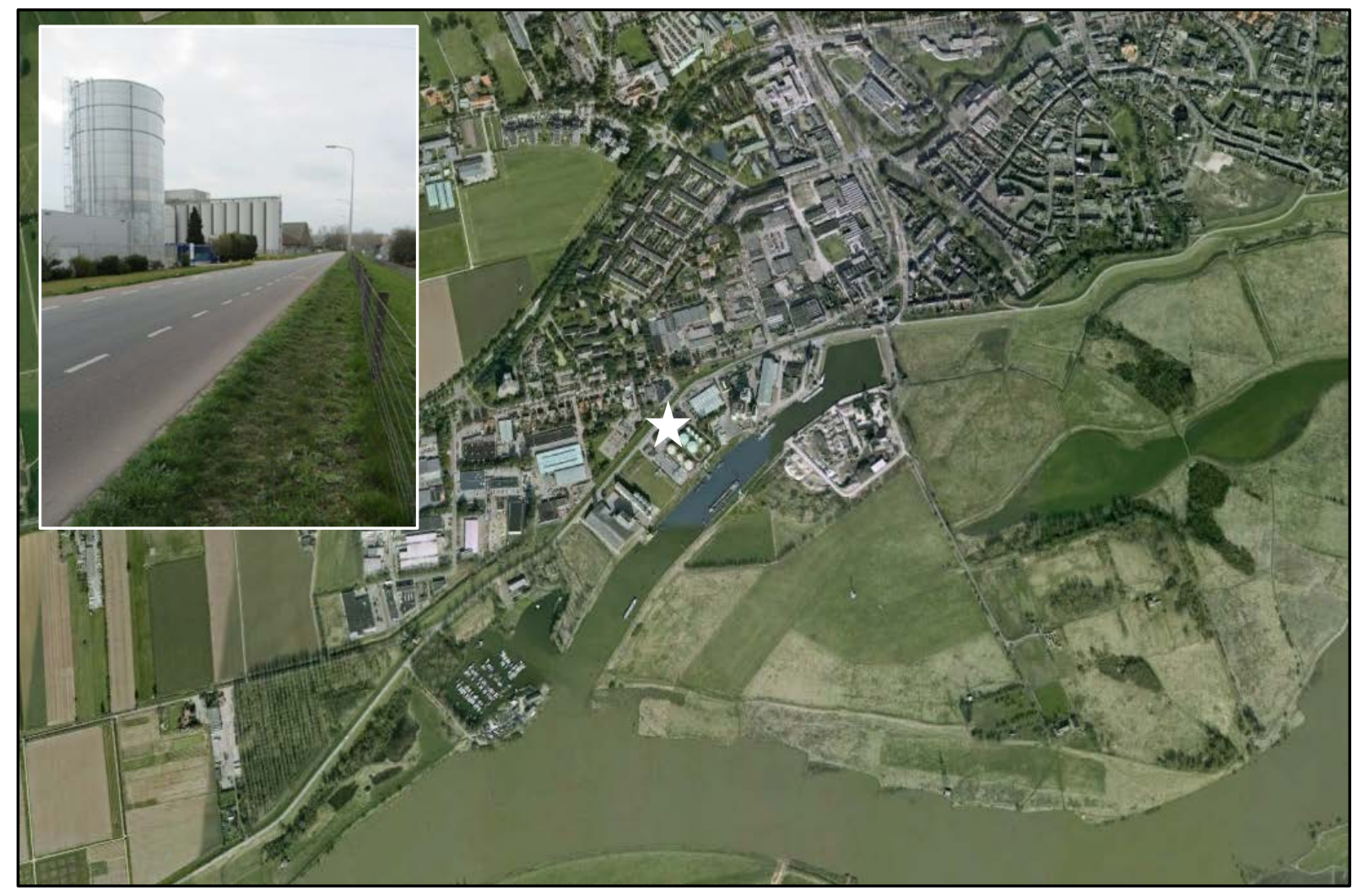


Situation Munnikenland

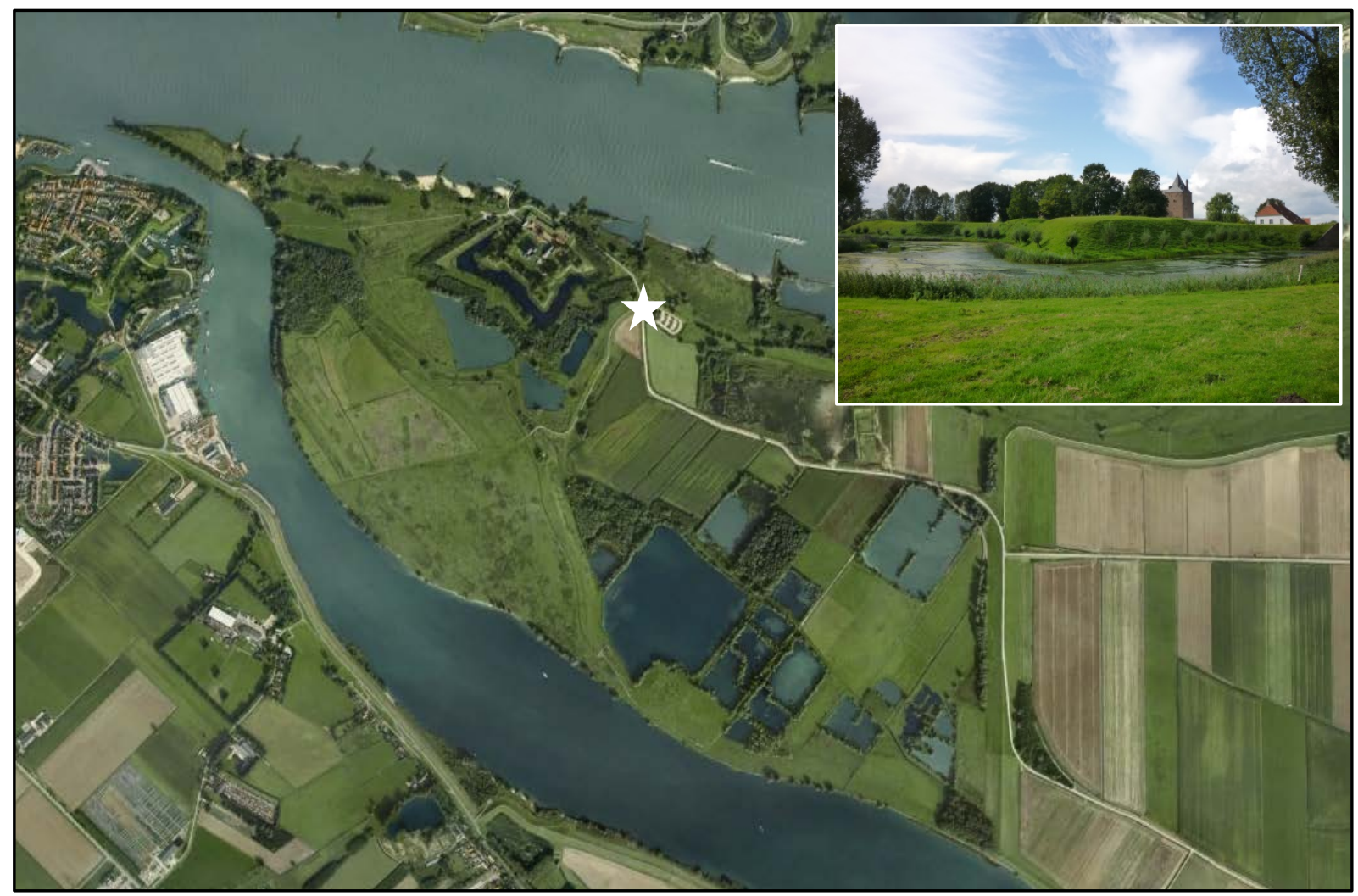

